\title{
An Artificial Intelligence Approach for Decision Making in Investment
}

\author{
Hegazy Zaher \\ Professor of Mathematical \\ Statistics \\ Institute of Statistical Studies \& \\ Research, Cairo University.
}

\author{
Naglaa Ragaa Saeid \\ Associated Professor of \\ Operations Researches \\ Institute of Statistical Studies \& \\ Researches, Cairo University
}

\author{
Walaa Moshref \\ Candidate of Master in Operations \\ Researches \\ Institute of Statistical Studies \& \\ Researches, Cairo University
}

\begin{abstract}
This paper considers decision making for fuzzy investments. A proposed client asset allocation model based on Mamdani FIS. The major aim of building such model is to help advising clients how to allocate portions of their investments in three types of assets, saving account, investment certificate and investment fund. The investment advisory models are applied with the goal of maximizing the expected return under two constraints, client's risk and age. The investment decisions can be undertaken when the aggregated if-then rules are applied in Mamdani FIS. A comparison between using different types and number of membership functions is outlined.The types of membership functions used are triangular MF ,Trapizodial MF and mixing between both triangular an trapizodial MF. It was found that using the MFs of the same kind triangular MF only or trapezoidal MF only give better expected returns than mixed MFs. The work is accompanied by an illustrative case study that show the validity of the approach, followed by some recommendations for future research area.
\end{abstract}

\section{Keywords}

Fuzzy investment, Mamdani Fuzzy Inference system, assets allocation $\&$ decision making in investment or finance.

\section{INTRODUCTION}

Decision making plays a key role in both scientific and realworld applications. Under the challenges possessed by linguistic imprecision and ambiguity of human being's judgment [24], it is crucial for decision makers to use some rigorous techniques and artificial intelligence tools from which they will use to make informed investment decisions. In general, we deal with problems in terms of systems that are constructed as models of some aspects of reality. There are three purposes for constructing such models: (i) to understand some phenomenon of reality, being either natural or manmade; (ii) to make adequate predictions; and (iii) to learn how to control the phenomenon in any desirable way and utilize all these capabilities for various ends [15].

Artificial intelligent (AI) is a discipline that attempts to understand the intelligent behavior in a broadest sense using computer to produce machines that behave intelligently; no matter what their underlying mechanism was [3]. AI is considered as an essential basis for building an inference system (IS) that begins with studying the problem's structure followed by activating the proper reasoning actions within that structure [27]. Fuzzy logic has been useful for various fields, such as theory of control of artificial intelligence. Fuzzy inference system (FIS) is a method of DM in which fuzzy logic designates a particular kind of inference calculus based on fuzzy sets. In FIS, the fuzzification of classical (crisp) uses human expertise, by sorting its essential components in the rule base, and performs defuzzification to infer the overall output value [22].

Once the assessment of performance of the fuzzy investment advisory models is carried out, the investment manager can advise clients how to allocate their investments into three different types of tangible assets: saving account, investment certificates, and investment funds. Asset allocation involves selecting a mix of investment appropriate to risk tolerance and age (time horizon). Hence elevates the role of building an artificial intelligent model to take the advantage of maximizing the expected return, that is constrained by clients' age and risk (input fuzzy variables) instead of building conventional mathematical model to represent the investment problem. This approach captures the knowledge- based expert judgments. Additionally, a notable feature of Mamdani FIS model is that a Mamdani FIS enables decision makers to integrate the analysis of quantitative and qualitative factors. A real case study is given to validate the proposed approach, where the MATLAB R2010a fuzzy logic toolbox is utilized, and a real data set from a private Bank in Egypt is used for illustrative purposes in conclusion. This paper is structured as follows. In Section 2, "Investment Problem" is presented. Section 3 contains "Fuzzy Set Theory". In section 4, considers "A proposed Fuzzy investment model". Finally, in Section 5 "Conclusions".

\section{INVESTMENT PROBLEM}

Asset allocation is a technique with which a mix of alternative investments, often long- term investment and mainly driven by client's risk tolerance and age "time horizon", are selected to get the best of risk/return tradeoff in the portfolio of investment.The strategic asset allocation decision effectively defines the aggregate level of risk and the potential or expected return of the overall investment portfolio. Asset allocation has long been viewed as a safe bet for reducing risks in a portfolio. Lee introduces the simple one-period portfolio optimization approach to demonstrate the importance of tactical asset allocation in maximizing expected utility[16]. He assumes that the investor measures utility by the total return and total risk of portfolio and specifies objective function in terms of expected return and variance of portfolio. Other researchers as Liu et al provide analytical solutions to the optimal portfolio problem in accordance with dynamic asset allocation with event risk[18]. This paper draws the attention to 3 classes of assets, often observed in investment: saving account, investment certificates, and investment funds, and question their usefulness. The terms of 
linguistic variables risks, savings, income, and growth, i.e. fuzzy concepts mentioned in [2] are substituted by saving accounts, investment certificates, and investment funds, respectively to help advise clients how to allocate portions of their investments. Each asset class behaves differently over time are verified by expecting each class to display different levels of risk and return [2]. Enabling asset allocators whether buyers or sellers to be capable of working as part of a group is not a case of working harder but working differently. However, knowing how to reap this benefit or indeed knowing how to invest money in what so-called "investment funds" has proven quite a challenge in the private banks since they display the highest risk levels despite offering the highest potential (or expected) returns over other asset classes. Nevertheless, if a young investor saves with plenty of time, s/he may want to invest more portions in an investment fund than in an investment certificate because the investment fund offers higher potential returns than the investment certificate despite being more risky. The proposed approach assigns two fuzzy linguistic variables 'age' and 'risk tolerance' as fuzzy input variables and measure them on suitable scales. Age is partitioned into three groups, for instance young, middle age and old. The researcher relied on data from a private bank to determine the risk tolerance within four intervals: [Low, High], [Low, Moderate, High], [Low, Moderate, High, Very high], [Very low, Low, Moderate, High, Very high], where the risk tolerance is partitioned on a psychometric scale from 0 to 100 .

In this paper, instead of trying to build conventional mathematical model to represent the investment problem, An intelligent model using fuzzy approach is presented.

\subsection{Preliminaries}

In the following, definitions of variables, which are necessary for this paper

Definition 1. Age: A time-based indicator, which indicates the time horizon (in years) during which the clients of various ages (young, middle age or old) may invest their money. The time horizon represents the expected date at which cash can be withdrawn from the fund which is associated with each fund. The farther the investor's time horizon, the more uncertainty there is [19].

Definition 2. Risk Tolerance: The extent to which an investor is willing to accept more share in risk provided she/he will get a higher return in exchange. It changes as a function of the decreasing time to horizon. Typically, the risk tolerance decreases as the fund approaches the time horizon, e.g., investments become more conservative towards the end of life of the fund. Older individuals tend to be less risk tolerant than younger individuals since they have less time to meet their goals and objectives [9]. However, the relationship between risk tolerance and age may not necessarily be linear [1]. In contrast, it was found that the level of risk tolerance decreases as age increases [10].

The clients can be categorized into three classes: i) risk averse, who prefers lower returns with known risk to higher returns with unknown risks; ii) aggressive investor, who seeks Risk or who has a high-risk tolerance and is more likely to risk losing money in order to get higher returns and iii) risk neutral, who is less likely to risk losing money to gain higher returns in exchange.

Definition 3. Saving Account: A deposit account held at any bank or in any financial institutions to take advantage of being the safest kind of investment, but offering the lowest return among three major classes of assets. Hence, the chances of losing money on an investment are extremely low.[Sherraden, M. and Schreine, M., 2003].

Definition 4. Investment Certificate: A certificate allows the investor to make an investment and earn a guaranteed rate of interest for a predetermined period of time. If the investor wants to break up the certificate before its due data for any reason, s/he would have the risk of losing an amount of interest in turn. Due to this reason only investment certificates guarantee more rate of interest than the corresponding rate for saving account. [32].

Definition 5. Investment Fund:An investment fund is a way of investing money alongside other investors in order to benefit from the inherent advantages of working as part of a group. An investment fund may offer the highest returns but with the highest risk. The clients would like the fund in which they invest to use its judgment to maximize risk-adjusted expected returns [6].

\section{FUZZY SET THEORY}

Fuzzy set and fuzzy logic theories have been an object of research since the 1960's. This great deal of interest is devoted to Lotfi A. Zadeh whose workouts geared towards developing fuzzy set theory[35].

fuzzy modeling can be recognized as the most adoptable approach for human information processing, which expresses the vagueness with appropriate mathematical tools.

It is worth mentioning that in fuzzy set theory the imprecise knowledge is effectively modeled by using linguistic values and degrees of membership. Therefore, it is extensively applied in real-world applications that cannot be described and handled by classical set theory. Fuzzy set theory is a powerful technique for handling the sources of imprecision and uncertainty that are non-classical in nature. It was developed an interactive method for multiple attribute group decision making GDM dealing with exact numerical and triangular fuzzy numbers[34]. The triangular fuzzy numbers are used to evaluate the suitability of personnel and the approximate reasoning of linguistic values.

\subsection{Fuzzy Logic and Fuzzy Operations}

The theory of fuzzy logic was first introduced by Lotfi A. Zadeh to model the uncertainity of the natural language[35]. Fuzzy logic plays an important role when applied to complex phenomena not easily described by traditional mathematics, so it is used to model uncertain natural systems like investment (or finance) to facilitate decision making by means of approximate reasoning and linguistic terms [24].

A fuzzy set $\widetilde{A}$ in a universe of discourse $X$ is defined by a membership $\mu_{\widetilde{A}}(x)$ which associates with each element $x$ in $X$ a real number in the interval $\mu_{\widetilde{A}}(x): X \rightarrow[0,1]$ [35]. Several set-theoretic operations involving fuzzy sets proposed by Zadeh are called the basic Zadeh operations [35]. The standard fuzzy intersection (min operator) produces for any given fuzzy sets the largest fuzzy set from among those produced by all possible fuzzy intersections ( $\mathrm{r}$-norms). The standard fuzzy union (max operator) produces, on the contrary, the smallest fuzzy set among the fuzzy sets produced by all possible fuzzy unions ( $\mathrm{t}$-conorrns). That is, the standard fuzzy operations occupy specific positions in the whole spectrum of fuzzy operations: the standard fuzzy intersection is the weakest fuzzy intersection, while the standard fuzzy union is the strongest fuzzy union [15].

Fuzzy sets and fuzzy logic are powerful mathematical formalized tools used to deal with uncertainty problems in 
terms of vagueness, imprecision, nonspecific, ambiguities, etc. [Chaturvedi, 2008] and to model uncertain industrial, human and natural systems [24]. Overall, there seems to be some evidence to indicate that fuzzy sets and fuzzy logic are extensively applied to model uncertain systems when there is ambiguous and imprecise information [35], [31].

\subsection{Fuzzy Inference System}

In 1975 fuzzy inference system (FIS) was originated and developed by Ebrahim Mamdani to solve a control problem of steam engine and boiler combination by synthesizing a set of linguistic control rules obtained from experienced human operators [20].Mamdani's work based on a paper by Lotfi Zadeh published in 1973 concerning fuzzy algorithms for complex systems and decision processes has inspired other researchers to explore the applicability of fuzzy systems [36],[2]. According to Mitra et al., 'Fuzzy Inference Systems (FIS) is the process of formulating membership function, logical operations, and IF-THEN rules and mapping from a given input to an output using fuzzy logic; this mapping provides a basis from which decisions can be made' [22][26]. As the name implies, FIS infers the output fuzzy variables from the input fuzzy variables based on a set of fuzzy logic inference rules in linguistic terms that are extracted from the knowledge base of fuzzy system. The knowledge base of a FIS is composed of fuzzy sets and fuzzy rules form. The inference engine based on mapping from a given input variable to an output variable provides a basis from which decisions can be made. Moreover, the FIS is one of the most popular practical tools based on the concept of fuzzy set theory to handle nonlinear, but ill-defined, mapping of input variables to some output ones [24]. It has been used in many fields like control, decision support system identification, engineering etc. [25] due to its closeness to human perception and reasoning, which are important factors for acceptance and usability of the system [23]. Due to its multidisciplinary nature, a variety of names have been associated with FIS such as fuzzy - rule-based systems, fuzzy expert systems, fuzzy logic controllers, fuzzy associative memory, fuzzy modelling and fuzzy systems [22].

Mamdani introduced a general FIS scheme including both input and output variables and five functional blocks including (i) a fuzzification interface which tranforms real numbers of input into fuzzy sets with linguistic variables such as low, medium, and high. (ii) a database which determines the MFs applied in the fuzzy rules (iii) a fuzzy rule base which has a number of fuzzy IF ... THEN rules that include all possible fuzzy relationships between inputs and outputs. Both (i) and (ii) are jointly referred to as the knowledge base (iv) an inference engine (or decision making unit) which helps to achieve inference operations on the rules and (v) a defuzzification interface which decodes (or conveys) the fuzzy outputs to crisp values [30], [27],[29]. From a general point of view, fuzzy IF-THEN rules and fuzzy reasoning are the backbone of FIS [22]. In FIS the membership function, logical operations, and fuzzy IF-THEN rules define mapping from fuzzy sets in the input space (input universe of discourse) $\mathrm{U} \subset \mathrm{R}^{\mathrm{n}}$ to fuzzy sets in the output space (output universe of discourse) $\mathrm{V} \subset \mathrm{R}$ based on fuzzy logic principles to model the qualitative aspects of human knowledge without using precise quantitative analyses [7],[26].

In finance and management, the prospective role or FIS was recognized only in the mid-1980s [4], and its full potential has not been fully realized as yet. Nevertheless, the number of publications dealing with applications of FIS in finance and management has been steadily growing. To mention a few, Pourjavad and Shahin present an FIS approach to the evaluation of Green Supply Chain Management GSCM Performance based on GSCM criteria and dimensions[24]. Liu and He (2013) present an integrated FIS approach to the estimation of environmental aspects in environmental management system, where life cycle assessment techniques are also employed. Israel et al present the Private Banking advisor (PB-ADVISOR) system and recommend the "multiinvestment portfolios" based on fuzzy and semantic technologies[12]. Lin and Chen monitor ecologically sensitive ecosystems in a dynamic semiarid landscape from satellite imagery using FIS[17]. Chen and Xu suggest fuzzy inference for analysis of structural systems under external excitations[5],[34]. Gupta et al. introduce a hybrid approach in which the behavior survey, the cluster analysis, the analytical hierarchy process and the fuzzy mathematical programming are combined together in a mathematical model that simultaneously consider both suitability and optimality in an asset allocation[11]. Ghazinoory outlines the portfolio analysis in their paper to develop the strategic decision making model, where its implementation is based on fuzzy set theory[8]. Shipley proposes a proactive fuzzy set-based model for assessing investments in terms of reacting to the risk inherent in investment activities relative to a complete view of portfolio management[28].

Owing to the ability of FIS(s) to generate fuzzy rules from a given input-output data set, two types of FISs, two best known FISs, labeled by their originators, are Mamdani-type FIS developed by Mandami and Takagi-Sugeno-Kang (TSK) type FIS proposed by Takagi and Sugeno [33],[21]. Both types vary somewhat in a way the outputs are determined in accordance with the construction of the rule consequent [20],[13]. The main distinction between them is in generating the crisp value; the output values have to be fuzzy in Mamdani type and crisp in TSK type. Moreover, Mamdani type FIS applies defuzzification techniques, but the TSK type FIS applies a weighted average and weighted sum methods for calculating the crisp output variables. [24], [22] mention that in Mamdani type FIS both the antecedent and the consequent are linguistic (fuzzy sets), but in the TSK type FIS the antecedent consists of fuzzy sets and the consequent is comprised of linear equations. Zaher et al. outline a comparison between Mamdani and Sugeno fuzzy methods for assessing which approach provides the best performance for predicting prices of Fund in the Egyptian market[37]. Mamdani and Takagi-Sugeno-Kang models have been widely used for solving problems such as decision analysis, expert systems, prediction (forecasting), data classification, image processing, optimization, and control and system identification. For more comparison and transformation [14].

\subsection{Mamdani FIS}

Mamdani FIS, the most commonly seen fuzzy methodology, was originally developed by Ebrahim Mamdani [20] for controlling application in the middle 1970s in which it controls a steam engine and boiler combination by synthesizing a set of linguistic control rules obtained from experienced human operators [2].

Mamdani-type FIS has been successfully used in a variety of investment problems. Mitra et al. highlights the great advantages of Mamdani FIS: (i) it is suitable for engineering systems where both inputs and outputs are realvalued variables, (ii) provides a natural framework to incorporate fuzzy IF-THEN rules from the human experts, and (iii) there is much freedom in the choice of fuzzifier, 
fuzzy inference engine, and defuzzifier, so that we can obtain the most suitable fuzzy logic system for a particular problem[22].

In Mamdani FIS, both the antecedent and the consequent are linguistic (fuzzy sets). Mamdani-type inference, as defined for the toolbox, expects the output membership functions to be fuzzy sets. After the aggregation process, there is a fuzzy set for each output variable that needs defuzzification, which will be discussed later in the next section. Figure1 displays the main components of a Mamdani fuzzy inference system.

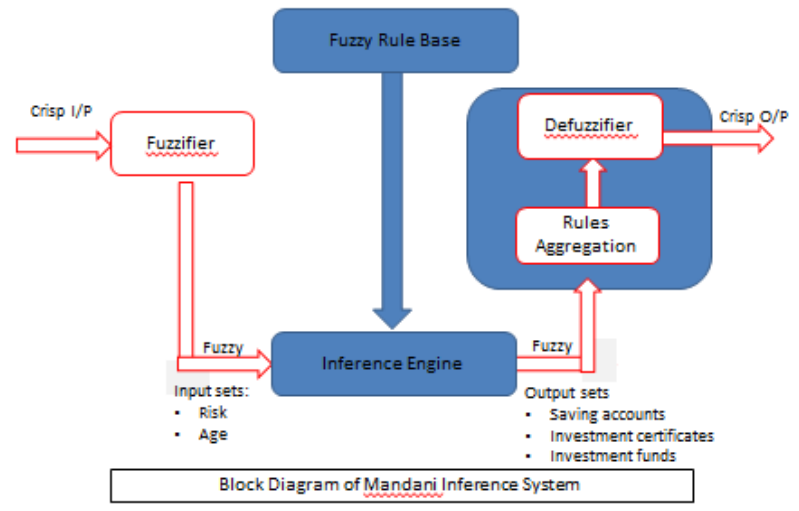

Figure1 Components of Mamdani FIS model .

\section{A PROPOSED FUZZY INVESTMENT MODEL}

This section is devoted to implement fuzzy logic client asset allocation model based on the observations collected from a private bank in Egypt and validated between December, 2016 and February, 2018.

The following steps illustrate fuzzy inference system:

\section{Step 1. Define and name both the input and output fuzzy} variables

The fuzzy logic client asset allocation model is a two inputthree-output model, where the input values under study were two fuzzy variables: age (three intervals) which varied from and Risk tolerance, the output values (linguistic variables) under study were three types of assets: saving account, investment certificate, and investment fund (three intervals for each).

\section{Step 2. Determine the membership functions}

Next, these measurements are converted into appropriate fuzzy sets to express measurement uncertainties. This step is called a fuzzification in which the membership functions are defined on the input variables under study (age and risk) and applied to their actual values to determine the degree of truth of each rule antecedent. These functions contain specified domain of the input value and can be shown in the form of triangles, trapezoids. The higher degrees of membership result in corresponding rules, which have more strength in the final computational process [22].

\section{Step 3. Generate a set of linguistic rules (IF-THEN rules).}

The fuzzy rule base is a fuzzy set of rules of the IF-THEN form. Fuzzy IF-THEN rules include two parts: the IF part which refers to the degree of membership in one of the fuzzy sets (antecedent), and the THEN part which refers to the consequent or the associated system output fuzzy set. The fuzzy inference engine uses these rules to determine the mapping from fuzzy sets in the input universe of discourse to fuzzy sets in the output universe of discourse based on fuzzy logic principles. The determination of the number of IFTHEN rules is based on the number of input values and fuzzy sets of MFs. One fuzzy IF-THEN rule can be written as

If (age is young )AND( risk is low)THEN asset allocation is medium in saving account, medium in investment certificate, medium in investment fund; age and risk are the inputs. Saving accounts, investment certificates, investment funds are the outputs. Young, low\& medium: Linguistic terms with MFs Triangular, Trapezoidal .

\section{Step 4. Aggregate all the rules}

The output of each fuzzy inference rule is combined into geometrical output to determine a fuzzy output value (decision). Here, the aggregation process is using the fuzzy operator " AND".

\section{Step 5. Defuzzify using centroid of gravity}

After the aggregation process, defuzzification is necessary for each output variable to transform (or decode) an output fuzzy set to a crisp value for each inference. Center of Gravity (COG) method is a popular methods for defuzzification, also called the center (or centroid) of area method (CAM). Let $\mathrm{z}$ be the output of the aggregation process. Assume that there are $\mathrm{N}$ membership values for $\mathrm{N}$ singleton output fuzzy sets in the rules (one value for each rule). Suppose that these fuzzy sets are nonzero only $z=\beta_{1}, \beta_{2}, \ldots, \beta_{N}$, where $\beta_{i}$ is the final fuzzy value associated with each outcome the defuzzifier produces the following defuzzifican output:

$$
z=\frac{\sum_{i=1}^{N} \mu_{i} \beta_{i}}{\sum_{i=1}^{N} \mu_{i}}
$$

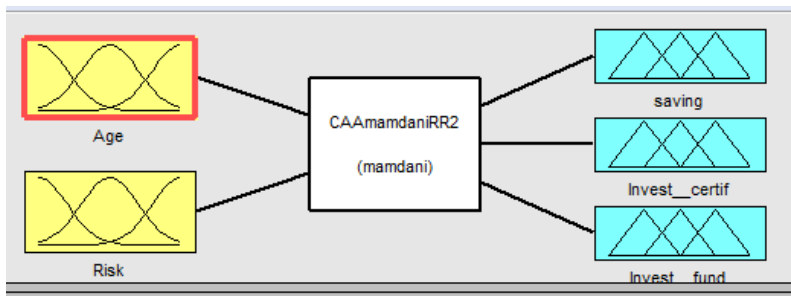

Figure 2: Fuzzy inference system (FIS) editor.

First Mamdani-type FIS is called CAAmamdaniRR2 shown in Figure 2, where the input variable risk contains 2 MFs (in bold) depicted in Figure 4 and written as follows

Age $={ }^{\Delta}\{\mathrm{Y}$ (young), MI (middle age), OL (old) $\}$

\section{Risk $={ }^{\Delta}\{\mathbf{L}$ (low), H (high) $\}$}

Saving account $={ }^{\Delta}\{\mathrm{L}$ (low), M (medium), H (high) $\}$, Investment certificates $={ }^{\Delta}\{\mathrm{L}$ (low), M (medium), H (high) $\}$ Investment funds $={ }^{\Delta}\{\mathrm{L}$ (low), M (medium), $\mathrm{H}$ (high) $\}$.

The two input and three output variables are described by the terms triangular and trapezoidal shapes shown in Figures 3:5. 


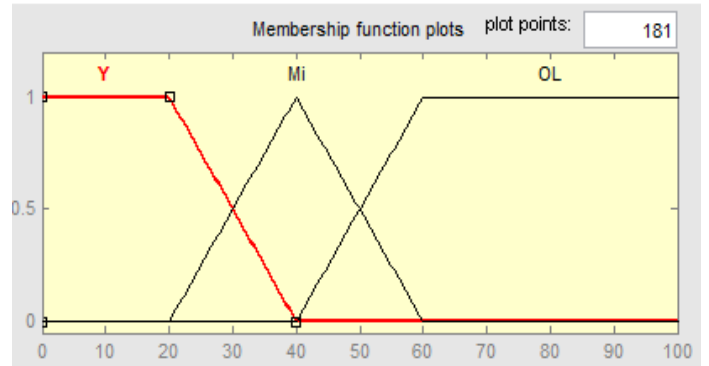

Figure 3: Triangular and trapezoidal MFs of input variable Age

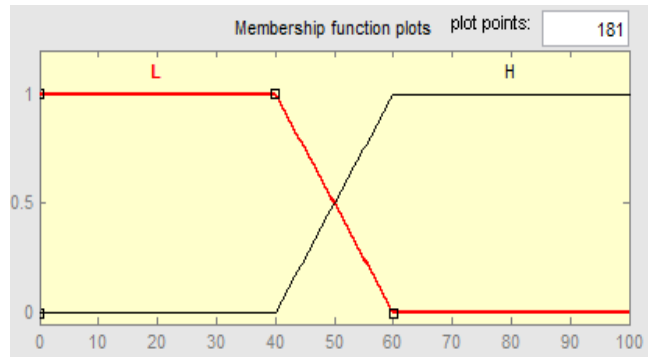

Figure 4: Triangular and trapezoidal MFs of input variable Risk

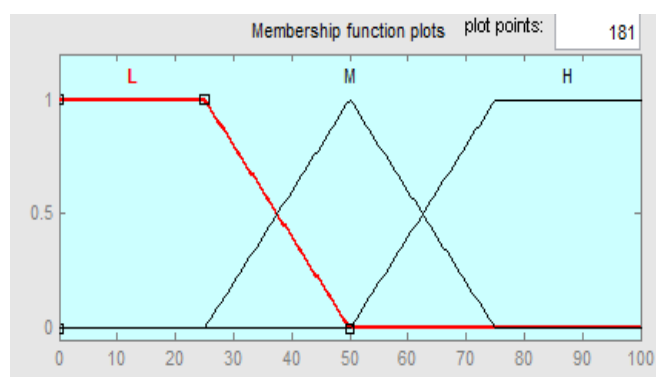

Figure 5: Triangular and trapezoidal MF of output variables saving account, investment certificate \& investment fund

There are six if ... and ... then rules, each of which produces three conclusions (one for each output), i.e., one for saving account, one for investment certificates, and one for investment funds. So the researcher constructed three decision tables, i.e. one for each output shown in Tables 1:3.

Table1. Decision table for the output saving accounts

\begin{tabular}{|c|c|c|}
\hline Age Risk & Low & High \\
\hline Young & $\mathrm{M}$ & $\mathrm{L}$ \\
\hline Middle & $\mathrm{M}$ & $\mathrm{L}$ \\
\hline Old & $\mathrm{H}$ & $\mathrm{M}$ \\
\hline
\end{tabular}

Table 2. Decision table for the output investment certificates

\begin{tabular}{|c|c|c|}
\hline Age Risk & Low & High \\
\hline Young & $\mathrm{M}$ & $\mathrm{L}$ \\
\hline Middle & $\mathrm{H}$ & $\mathrm{M}$ \\
\hline Old & $\mathrm{H}$ & $\mathrm{M}$ \\
\hline
\end{tabular}

Table 3. Decision table for the output investment funds

\begin{tabular}{|c|c|c|}
\hline Age Risk & Low & High \\
\hline Young & M & H \\
\hline Middle & L & H \\
\hline Old & L & M \\
\hline
\end{tabular}

The first two IF ... AND ... THEN rules read:

If client's age is young and client's risk tolerance is low, then asset allocation is: medium in saving account, medium in investment certificates, medium in investment funds.

If client's age is young and client's risk tolerance is high, then asset allocation is: low in saving account, low in investment certificates, and high in investment funds.

Second Mamdani-type FIS is called CAAmamdaniRR3, where the input variable risk contains 3 MFs (low, moderate, high) written as follows

Risk $={ }^{\Delta}\{\mathrm{L}$ (low),Mo (moderate), H (high) $\}$,

The two input and three output variables are described by the terms of triangular and trapezoidal shapes.

There are nine if ... and ... then rules, each of which produces three conclusions (one for each output), i.e., one for saving account, one for investment certificates, and one for investment funds. So the researcher constructed three decision tables, i.e. one for each output shown in Tables 4:6.

Table 4. Decision table for the output saving account

\begin{tabular}{|c|c|c|c|}
\hline Age Risk & Low & Moderate & High \\
\hline Young & M & L & L \\
\hline Middle & M & L & L \\
\hline Old & H & M & M \\
\hline
\end{tabular}

Table 5. Decision table for the output investment certificates

\begin{tabular}{|c|c|c|c|}
\hline Age Risk & Low & Moderate & High \\
\hline Young & M & M & L \\
\hline Middle & H & H & M \\
\hline Old & H & H & M \\
\hline
\end{tabular}

Table 6. Decision table for the output investment funds

\begin{tabular}{|c|c|c|c|}
\hline Age Risk & Low & Moderate & High \\
\hline Young & M & H & H \\
\hline Middle & L & M & H \\
\hline Old & L & L & M \\
\hline
\end{tabular}


The first two IF ... AND ... THEN rules read:

If client's age is young and client's risk tolerance is low, then asset allocation is: medium in saving account, medium in investment certificates, medium in investment funds

If client's age is young and client's risk tolerance is moderate, then asset allocation is: low in saving account, medium in investment certificates, high in investment funds.

Third FIS is called CAAmamdaniRR4, where the input variable risk contains 4 MFs (low, moderate, high, and very high) written as

Risk $={ }^{\Delta}\{\mathrm{L}$ (low),Mo (moderate), H (high), Vh (very high) $\}$,

The two input and three output variables are described by the terms of triangular and trapezoidal shapes.

There are twelve if ... and ... then rules, each of which produces three conclusions (one for each output), i.e., one for saving account, one for investment certificates, and one for investment funds. So the researcher constructed three decision tables, i.e. one for each output shown in Tables 7:9.

Table 7 Decision table for the output saving account

\begin{tabular}{|c|c|c|c|c|}
\hline Age $\backslash$ Risk & Low & Moderate & High & $\begin{array}{c}\text { Very } \\
\text { high }\end{array}$ \\
\hline Young & M & L & L & L \\
\hline Middle & M & L & L & L \\
\hline Old & H & M & M & M \\
\hline
\end{tabular}

Table 8. Decision table for the output investment certificates

\begin{tabular}{|c|c|c|c|c|}
\hline Age Risk & Low & Moderate & High & $\begin{array}{c}\text { Very } \\
\text { high }\end{array}$ \\
\hline Young & M & M & M & L \\
\hline Middle & H & H & H & M \\
\hline Old & H & H & M & M \\
\hline
\end{tabular}

Table 9 Decision table for the output investment funds

\begin{tabular}{|c|c|c|c|c|}
\hline Age \Risk & Low & Moderate & High & $\begin{array}{c}\text { Very } \\
\text { High }\end{array}$ \\
\hline Young & M & H & H & H \\
\hline Middle & L & M & H & H \\
\hline Old & L & L & L & M \\
\hline
\end{tabular}

The first IF ... AND ... THEN rule read:

If client's age is young and client's risk tolerance is low, then asset allocation is: medium in saving account, medium in investment certificates, medium in investment funds.

Fourth FIS is called CAAmamdaniRR5, where the input variable risk contains 5 membership functions (very low, low, moderate, high, very high) depicted in Figure 6:

Risk $=\Delta\{$ Vl (very low),L (low),Mo (moderate), H (high), Vh (very high)\},

The two inputs and three outputs are described by the terms of triangular and trapezoidal shape as shown in Figure 6.

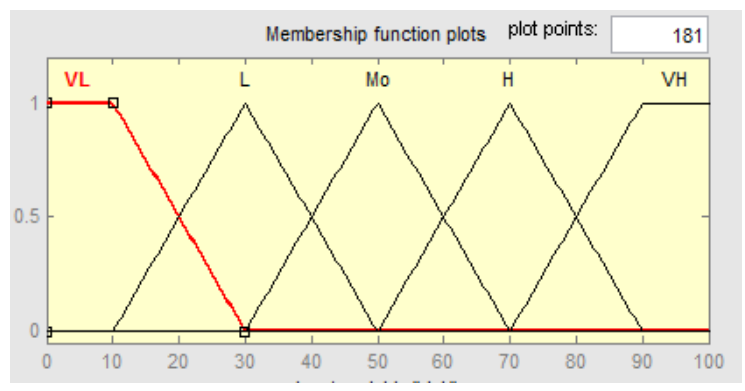

Figure 6: Five Triangular and trapezoidal MFs of input variable risk

There are fifteen if ... and ... then rules, each of which produces three conclusions (one for each output), i.e., one for saving account, one for investment certificates, and one for investment funds. So the researcher constructed three decision tables, i.e. one for each output shown in Tables 10:12.

Table 10 Decision table for the output saving account

\begin{tabular}{|c|c|c|c|c|c|}
\hline Age Risk & $\begin{array}{c}\text { Very } \\
\text { Low }\end{array}$ & Low & Moderate & High & $\begin{array}{c}\text { Very } \\
\text { High }\end{array}$ \\
\hline Young & M & L & L & L & L \\
\hline Middle & M & L & L & L & L \\
\hline Old & H & H & M & M & M \\
\hline
\end{tabular}

Table 11 Decision table for the output investment certificates

\begin{tabular}{|c|c|c|c|c|c|}
\hline Age Risk & $\begin{array}{c}\text { Very } \\
\text { Low }\end{array}$ & Low & Moderate & High & $\begin{array}{c}\text { Very } \\
\text { High }\end{array}$ \\
\hline Young & M & M & M & M & L \\
\hline Middle & H & H & H & H & M \\
\hline Old & H & H & H & M & M \\
\hline
\end{tabular}

Table 12 Decision table for the output investment funds

\begin{tabular}{|c|c|c|c|c|c|}
\hline Age Risk & $\begin{array}{c}\text { Very } \\
\text { Low }\end{array}$ & Low & Moderate & High & $\begin{array}{c}\text { Very } \\
\text { High }\end{array}$ \\
\hline Young & M & M & H & H & H \\
\hline Middle & L & L & M & H & H \\
\hline Old & L & L & L & L & M \\
\hline
\end{tabular}

The first IF ... AND ... THEN rule read:

If client's age is young and client's risk tolerance is very low, then asset allocation is: medium in saving account, medium in investment certificates, medium in investment funds

Using Excel sheet in conjunction with MATLAB R2010a, the Average Expected Return is calculated. Table 13 shows rule one average expected returns. The same calculations repeated for the rest of the fifteen rules 
Table 13 the Average Expected Return CAARR5 model

\begin{tabular}{|c|c|c|c|c|c|c|c|c|}
\hline & & & & $\begin{array}{l}\text { \%Int. } \\
\text { Rate }\end{array}$ & 7.5 & 11.5 & 15 & \\
\hline \multicolumn{6}{|c|}{$\begin{array}{l}\text { Fuzzy Inference system : } \\
\text { CAAmamdaniRR5 }\end{array}$} & & & \\
\hline $\begin{array}{l}15 \\
\text { Rul } \\
\text { e }\end{array}$ & & & & & & & & \\
\hline $\begin{array}{l}\mathrm{Ag} \\
\mathrm{e} \\
\mathrm{x}\end{array}$ & $\begin{array}{l}\text { Ris } \\
\mathrm{k} \\
\mathrm{y}\end{array}$ & $\begin{array}{l}\text { Sa } \\
\text { v. } \\
\text { acc }\end{array}$ & $\begin{array}{l}\text { Inves } \\
\text { t. } \\
\text { certif } \\
\text {. }\end{array}$ & $\begin{array}{l}\text { Inves } \\
\text { t. } \\
\text { fund }\end{array}$ & $\begin{array}{l}\% \\
\text { Sav. } \\
\text { acc. }\end{array}$ & $\begin{array}{l}\text { \% } \\
\text { Inves } \\
\text { t. } \\
\text { certif }\end{array}$ & $\begin{array}{l}\% \\
\text { Inves } \\
\text { t. } \\
\text { fund }\end{array}$ & $\begin{array}{l}\text { CAAR } \\
\text { R5 } \\
\text { Exp. } \\
\text { return }\end{array}$ \\
\hline \multicolumn{8}{|c|}{ Rule 1: ( young, very low) } & \\
\hline 10 & 10 & 50 & 50 & 50 & $\begin{array}{c}33.3 \\
3\end{array}$ & $\begin{array}{c}33.3 \\
3\end{array}$ & $\begin{array}{c}33.3 \\
3\end{array}$ & $\begin{array}{c}1133.3 \\
3\end{array}$ \\
\hline 10 & 20 & $\begin{array}{c}34 . \\
2\end{array}$ & 50 & 50 & $\begin{array}{c}25.4 \\
8\end{array}$ & $\begin{array}{c}37.2 \\
6\end{array}$ & $\begin{array}{c}37.2 \\
6\end{array}$ & $\begin{array}{c}1178.4 \\
6\end{array}$ \\
\hline 20 & 10 & 50 & 50 & 50 & $\begin{array}{c}33.3 \\
3\end{array}$ & $\begin{array}{c}33.3 \\
3\end{array}$ & $\begin{array}{c}33.3 \\
3\end{array}$ & $\begin{array}{c}1133.3 \\
3\end{array}$ \\
\hline 20 & 20 & $\begin{array}{c}34 . \\
2\end{array}$ & 50 & 50 & $\begin{array}{c}25.4 \\
8\end{array}$ & $\begin{array}{c}37.2 \\
6\end{array}$ & $\begin{array}{c}37.2 \\
6\end{array}$ & $\begin{array}{c}1178.4 \\
6\end{array}$ \\
\hline 30 & 10 & 50 & 65.8 & 34.2 & $\begin{array}{c}33.3 \\
3\end{array}$ & $\begin{array}{c}43.8 \\
7\end{array}$ & $\begin{array}{c}22.8 \\
0\end{array}$ & $\begin{array}{c}1096.4 \\
7\end{array}$ \\
\hline 30 & 20 & $\begin{array}{c}34 . \\
2\end{array}$ & 65.8 & 34.2 & $\begin{array}{c}25.4 \\
8\end{array}$ & $\begin{array}{c}49.0 \\
3\end{array}$ & $\begin{array}{c}25.4 \\
8\end{array}$ & $\begin{array}{c}1137.2 \\
6\end{array}$ \\
\hline \multicolumn{5}{|c|}{ Rule 1 average } & $\begin{array}{c}29.4 \\
1\end{array}$ & $\begin{array}{c}39.0 \\
1\end{array}$ & $\begin{array}{c}31.5 \\
8\end{array}$ & $\begin{array}{c}1142.8 \\
9\end{array}$ \\
\hline
\end{tabular}

Determining the expected returns using Mamdani-type

Model three CAAmamdaniRR4 yields the highest average expected returns $(11.54 \%)$ among other fuzzy models using four MFs in the input variable risk. Reducing the number of MFs to only two MFs is shown in the CAAMamdaniRR2 model in which the rules were reduced as well as the average expected returns which is also decreased to be $11.33 \%$. Too much membership functions means increasing the rules that would also reduce the average expected returns as shown in the CAAMamdaniRR5 model in which it was decreased to $11.44 \%$.

In the next part all MFs in the input variables (Age and Risk) and in the output variables (saving account, investment certificate and investment fund) changed into Triangular MFs and examined their effect on the average expected returns.

First triangular FIS is called RR2tri, where the input variable risk contains 2 triangular MFs.

Using the same six IF ... AND ... THEN rules and the same three decision tables used before in CAAmamdaniRR2, the expected returns for the first triangular model RR2tri was $11.37 \%$.

Second triangular FIS is called RR3tri, where the input variable risk contains 3 triangular MFs.

Using the same nine IF ... AND ... THEN rules and the same three decision tables used before in CAAmamdaniRR3, the expected returns for the second triangular model RR3tri was $11.55 \%$.

Third triangular FIS is called RR4tri, where the input variable risk contains 4 triangular MFs.

Using the same twelve IF ... AND ... THEN rules and the same three decision tables used before in CAAmamdaniRR4, the expected returns for the third triangular model RR4tri was $11.63 \%$

Fourth triangular FIS is called RR5tri, where the input variable risk contains 5 triangular MFs as shown in Figure 7.

Using the same fifteen if...and ...then rules and the same three decision tables used before in CAAmamdaniRR5, the expected returns for the fourth triangular model RR5tri was $11.51 \%$.

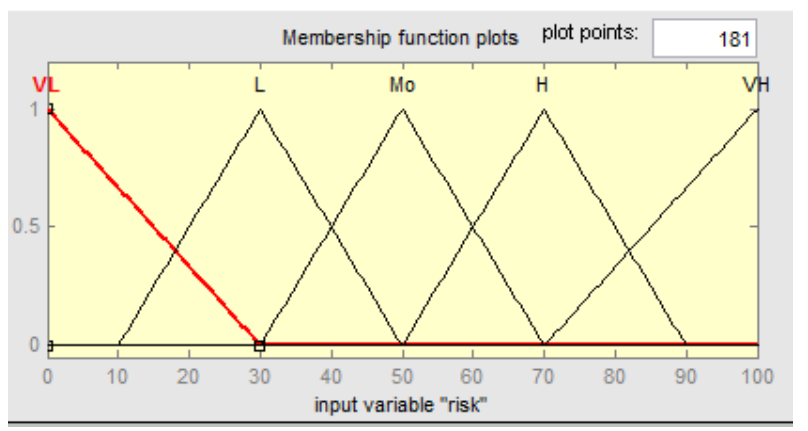

Figure 7: Five Triangular MF of input variable risk

In the next part all MFs in the input variables (Age and Risk) and in the output variables (saving account, investment certificate and investment fund) changed into trapezoidal MFs and examined their effect on the average expected returns.

First trapezoidal FIS is called RR3tri, where the input variable risk contains 2 trapezoidal MFs.

Using the same six IF ... AND ... THEN rules and the same three decision tables used before in CAAmamdaniRR2, the expected returns for the first trapezoidal model RR2trap was $11.35 \%$.

Second trapezoidal FIS is called RR3trap, where the input variable risk contains 3 trapezoidal MFs.

Using the same nine IF ... AND ... THEN rules and the same three decision used before in CAAmamdaniRR3, the expected returns for the second trapezoidal model RR3trap was $11.52 \%$.

Third trapezoidal FIS is called RR4trap, where the input variable risk contains 4 trapezoidal MFs.

Using the same twelve IF ... AND ... THEN rules and the same three decision tables aforementioned in CAAmamdaniRR4, the expected returns for the third trapezoidal model RR4trap was $11.57 \%$

Fourth trapezoidal FIS is called RR5trap, where the input variable risk contains 5 trapezoidal membership functions depicted in Figure 8.

Using the same fifteen IF ... AND ... THEN rules and the same three decisions tables used before in CAAmamdaniRR5, the expected returns for the fourth trapezoidal model RR5trap was $11.46 \%$.

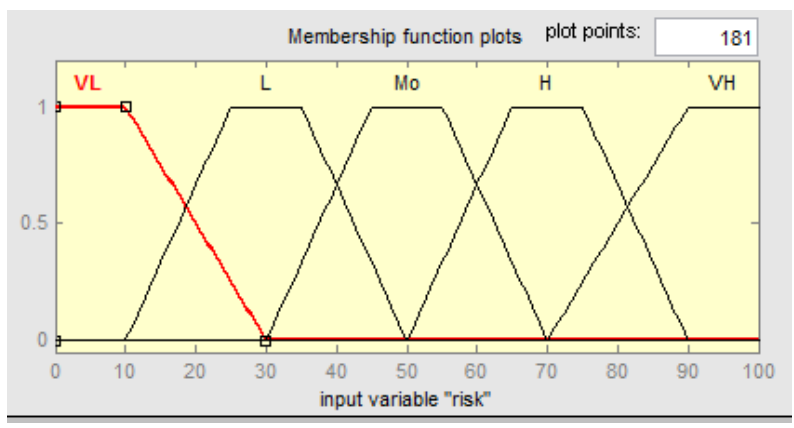

Figure 8: Five trapezoidal MF of input variable.

Table 14 shows the results of comparing different types and numbers of $\mathrm{MF}$ and their corresponding expected return 
illustrated in Figure 9.

Table 14. Comparison of expected returns percentage using different numbers and types of MF.

\begin{tabular}{|l|l|l|l|}
\hline $\begin{array}{r}\text { \%age of Expected } \\
\text { Return using } \\
\begin{array}{c}\text { No. of MF } \\
\text { in Risk Input }\end{array}\end{array}$ & $\begin{array}{l}\text { Triangular } \\
\text { MF }\end{array}$ & $\begin{array}{l}\text { Trapezoidal } \\
\text { MF }\end{array}$ & $\begin{array}{l}\text { Mixed } \\
\text { MF }\end{array}$ \\
\hline $2 \mathrm{MF}$ & 11.37 & 11.35 & 11.33 \\
\hline $3 \mathrm{MF}$ & 11.55 & 11.52 & 11.47 \\
\hline $4 \mathrm{MF}$ & 11.63 & 11.57 & 11.54 \\
\hline $5 \mathrm{MF}$ & 11.51 & 11.46 & 11.44 \\
\hline
\end{tabular}

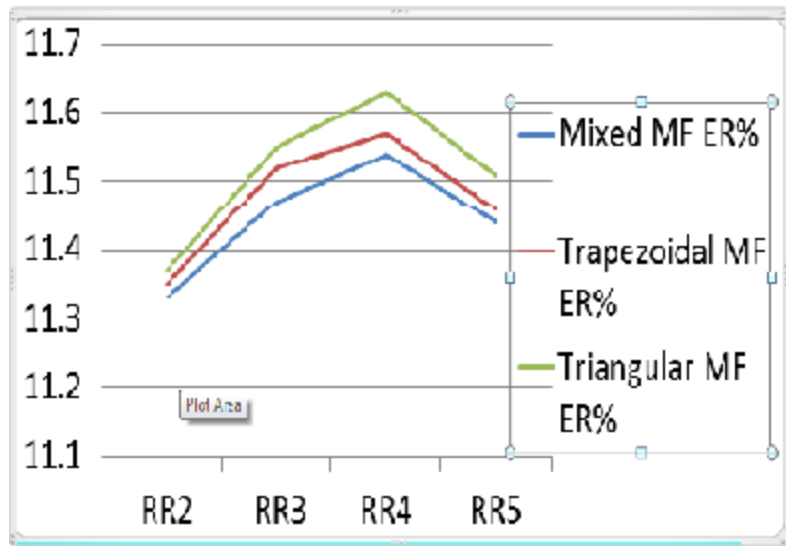

Figure 9: Different type and number of MF and their corresponding expected returns percentage.

\section{CONCLUSION}

This paper has examined the performance of Mamdani FIS using different types and numbers of MF. The MFs of the same type (triangular MF only or trapezoidal MF only) give better results of expected returns than the mixed MFs. The triangular MFs give the highest percentage of expected return. Thus the triangular membership function is recommended which suitable for data shape. Also, changing the number of MF has an effect on the expected returns. Four MFs in the risk input gives the highest average expected returns. Reducing the number of MFs to only two MFs, as shown in Figure 9, reflected a reduction in the number of rules as well as a decrease in the average expected returns. Too much MFs, as shown in table 14, reflected an increase in the number of rules that would reduce the average expected returns.

\section{REFERENCES}

[1] Bajtelsmit, V.and Derhei,V., 1997. Why do women invest differently than men?, pp.1-10

[2] Bojadziev G. and Bojadziev M., 2007. Fuzzy logic for business, finance, and management, Ed. 2, World Scientific Publishing Co. Pte. Ltd. ISBN-13 978-981270-649-2, ISBN-10 981-270-649-6

[3] Brighton, H., 2008. Introducing artificial intelligence, Totem Books. Published on Amazon.com

[4] Buckley, P.A., 1987. Epilogue and prologue:Past and future research in avian genetics. In Avian genetics: apopulation and ecological approach. Eduted by F. Cooke and P.A. Buckley. Academic Press, Orlando, Fla. Pp. 453-475

[5] Chen, B., Liu, X., Liu, K., Shi, P. , and Lin, C., 2010.
Direct adaptive fuzzy control for nonlinear systems with time-varying delays, Information Sciences, Vol. 180, pp. 776-792

[6] Chevalier, J.A. and Ellison, G.D., 1995. Risk taking by mutual funds as a response to incentives, NBER working paper No. 5234,

[7] Dubois, D. and Prade, H., 1978. Operations on fuzzy numbers, International Journal of Systems Science, Vol. 9, Issue 6, pp. 613-626

[8] Ghazinoory, S., Zadeh, A. E. and Kheirkah, A.S., 2010. Application of fuzzy calculations for improving portfolio matrices, Information Sciences, Vol. 180, Issue 9, pp. 1582-1590, ISSN 0020-0255.

[9] Grable, J. and Lytton, R.H., 1999. Financial risk tolerance revisited: The development of a risk assessment instrument, Financial Services Review, Vol.8, pp. 163-181.

[10] Grable, J.E., McGill, S., and Britt, S., 2009. Risk tolerance estimation bias: The age effect, Journal of Business and Economics Research, Vol. 7, Issue 7, pp.112

[11] Gupta, P., Mehlawat, M.K. and Saxena, A., 2010. A hybrid approach to asset allocation with simultaneous consideration of suitability and optimality, Information Sciences, Vol. 180, Isuue 11, pp. 2264-2285.

[12] Israel, G.C., Ricardo, C. P., Jose, L.L.C., Ángel, G. A. and Belén, R.M.. 2012, PB-ADVISOR: A private banking multi-investment portfolio advisor, Information Sciences, Vol. 206, pp. 63-82.

[13] Jang, J.S., Sun, C.T. and Mizutani, E., 1997. NeuroFuzzy and Soft Computing: A computational approach to learning and machine intelligence, Prentice Hall Inc, USA, pp. 73-91.

[14] Jassib, J. J., 2008. A Comparison of Mamdani and Sugeno Fuzzy Inference Systems for a Space Faulty Detection Application, IEEE, pp. 1-8

[15] Klir, G. J. and Yuan, B., 1995. Fuzzy set and fuzzy logic: theory and applications, Published by Prentice Hail International, Upper Saddle River, New Jersey, pp. 595

[16] Lee, W., 2000. Theory and methodology of tactical asset allocation, John Wiley \& Sons

[17] Lin, M.L., and Chen, C. W., 2010. Application of fuzzy models for the monitoring of ecologically sensitive ecosystems in a dynamic semi-arid landscape from satellite imagery, Engineering Computations, Vol. 27, Issue 1, pp. 5-19

[18] Liu, T., and He, J., 2013. A self-adapting fuzzy inference system for the evaluation of agricultural land, Environmental Modelling and Software, Vol. 40, pp. 226-234

[19] Luskin, D.L. and Tint, L.G., 1998. Investment fund management method and system with dynamic risk adjusted allocation of assets, US Patent and Trademark Office (USPTO).

[20] Mamdani, E.H. and Assilian, S., 1975. An experiment in linguistic synthesis with a fuzzy logic controller, International Journal of Man-Machine Studies, Vol. 7, 
Issue 1, pp.1-13.

[21] Mamdani, E.H., 1974. Application of fuzzy algorithms for simple dynamic plant, IEEE, Vol. 121, Issue 12, pp. 1585-1588

[22] Mitra, A.K., Nath, S. and Sharma, A.K., 2008. Fog forecasting using rule- based fuzzy inference system, Journal of the Indian Society of Remote Sensing, Vol.36, Issue 3, pp. 243-253

[23] Nauck, D and Kruse, R., 1999. Obtaining interpretable fuzzy classification rules from medical data, Artificial Intelligent in Medicine, vol. 16, pp. 149-169, Elsevier.

[24] Pourjavad, E. and Shahin, A., 2018. The application of Mamdani Fuzzy Inference System in Evaluating Green Supply Chain Management Performance, International Journal of Fuzzy System, Vol. 20, Issue 3, pp. 901-912

[25] Ross, T.J., 1995. Fuzzy logic with engineering applications, McGaw-Hill Inc., New York, pp. 579

[26] Rutkowski, L., 2008. Computational intelligence methods and techniques, Springer-Verlag Berlin Heidelberg

[27] Sabri1, N.; Aljunid1, S. A.; Salim, M. S., Badlishah, R. B.; Kamaruddin, R. and Abd Malek1 M. F., 2013. Fuzzy inference system: Short review and design, International Review of Automatic Control (I.RE.A.CO.), Vol. 6, Issu. 4, pp. 441-449

[28] Shipley M.F., 2009. Portfolio Management: A Fuzzy Set Based Approach to Monitoring Size to Maximize Return and Minimize Risk, World Academy of Science, Engineering and Technology International Journal of Computer and Information Engineering, Vol.3, Issue 4, pp. 1000-1007.

[29] Sivanandam S. N., Sumathi S. and Deepa S. N., 2007. Introduction to Fuzzy Logic using MATLAB, SpringerVerlag Berlin Heidelberg
[30] Sofyan, H., Rahmat, D., Marzuki, and Rusyana, A., 2015. Application of Mamdani FIS method for classification of Melinjo maturity according to its colour, Presented on The 11th IMT-GT International Conference on Mathematics, Statistics and Its Applications, Pattaya, Thailand.

[31] Soltani, A., and Haji, R., 2007. A project scheduling method based on fuzzy theory, Journal of Industrial and Systems Engineering, Vol. 1, Issue 1, pp. 70-80

[32] Steinberg, M.I., and Kaulbach, W. E, 1987. The Supreme Court and the definition of security: The context clause, investment contract analysis, and their ramifications, HeinOnline

[33] [33].Takagi, T. and Sugeno, M., 1985. Fuzzy Identification of Systems and its applications to modeling and control, IEEE Trans, on Systems, Man and Cybernetics, Vol.15, pp. 116-132

[34] Xu, Z.S. and Chen, J., 2006. An interactive method for fuzzy multiple attribute group decision making, Information Sciences, vol. 177, issue 1, 248-263 GDM

[35] [35].Zadeh, L.A., 1965. Fuzzy sets, Information and Control, Vol. 8, pp. 338-353.

[36] Zadeh, L.A., 1973. Outline of a new approach to the analysis of complex systems and decision processes, IEEE Transactions on Systems, Man, and Cybernetics, Vol. 3, Issue. 1, pp. 28-44

[37] Zaher, H.; Kandil, A.E., and Fahmy, R., 2014. Comparison of Mamdani and Sugeno Fuzzy Inference Systems for prediction (with application to prices of Fund in Egypt), British Journal of Mathematics \& Computer Science, SCIENCEDOMAIN international, Vol. 4, Issue 21, pp. 3014-3022. 